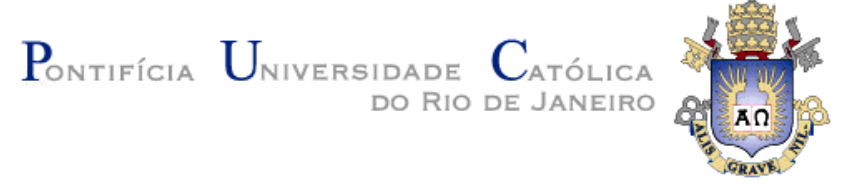

Sergio Carvalho de Assunção

\title{
FICÇÃO E FRICÇÃO EM WALY SALOMÃO
}

Tese de Doutorado

Tese apresentada ao Programa de Pós-graduação em Letras da PUC-Rio como requisito parcial para obtenção do título de Doutor em Letras.

Orientadora: Marília Rothier Cardoso

Rio de Janeiro 


\section{Pontifícia U Universidade Católloa DO RIO DE JANEIRO}

\section{Sergio Carvalho de Assunção}

\section{Ficção e fricção em Waly Salomão}

Tese apresentada como requisito parcial para obtenção do grau de Doutor pelo Programa de Pós-Graduação em Letras do Departamento de Letras do Centro de Teologia e Ciências Humanas da PUC-Rio. Aprovada pela Comissão Examinadora abaixo assinada.

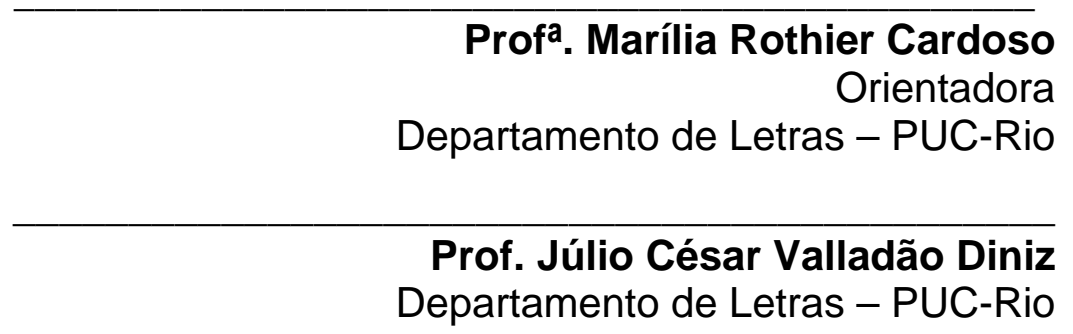

Prof. André Monteiro Guimarães Dias Pires Centro de Ensino Superior de Juiz de Fora - CESJF

Prof. Anderson Pires da Silva

Universidade Federal de Juiz de Fora - UFJF

Prof. Luiz Fernando Medeiros de Carvalho Universidade Estácio de Sá - UNESA

\footnotetext{
Prof. Paulo Fernando Carneiro de Andrade

Coordenador Setorial do Centro de Teologia

e Ciências Humanas - PUC-Rio
}

Rio de Janeiro, de de 
Todos os direitos reservados. É proibida a reprodução total ou parcial do trabalho sem autorização da universidade, do autor, e do orientador.

\section{Sergio Carvalho de Assunção}

Graduou-se em Letras pela Uerj em 2000. Defendeu Dissertação de Mestrado pela Puc-rio em 2003. É professor de Literatura desde 2003.

Ficha Catalográfica

Assunção, Sergio Carvalho de

Ficção e fricção em Waly Salomão / Sergio Carvalho de Assunção ; orientadora: Marília Rothier Cardoso. - 2008.

104 f. ; $30 \mathrm{~cm}$

Tese (Doutorado em Letras)-Pontifícia Universidade Católica do Rio de Janeiro, Rio de Janeiro, 2008.

Inclui bibliografia

1. Letras - Teses. 2. Waly. 3. Fricção. 4. Poesia. 5. Alquimia. 6. Música. I. Cardoso, Marília Rothier. II. Pontifícia Universidade Católica do Rio de Janeiro. Departamento de Letras. III. Título.

CDD: 800 


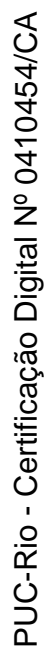

AO PAI.

À ELIZA, meu AMOR e VIDA, pela MAGIA e

POESIA de cada segundo ao seu lado. 


\section{Agradecimentos}

A alegria que sinto ao cumprir este ciclo, gostaria de dividir com algumas pessoas que, especialmente, destinaram parte de seu precioso tempo para minhas solicitações. Sem elas, creio que este trabalho não teria a mesma força. Sintam-se fortemente abraçadas por mim.

Sergio e Cecília Assunção, por todo amor e investimento incondicionais.

Cesinha Oiticica, pela colaboração crucial e pela alegria das histórias.

Omar e Khalid Salomão, pela atenção e delicadeza.

Ana Kiffer, pelo cuidado e rigor crítico da primeira leitura.

Marília, pela atenção, paciência e intervenções precisas.

Julio Diniz (Julinho), pela crítica estimulante e valiosa.

Anderson (Songs), pela alegria, amizade e rock’n’roll.

André Monteiro (Deco), pelo respeito, leveza e amizade.

Luiz Fernando (Lufa), pela generosidade, pela magnitude e poesia.

Jorge Máximo, pela motivação, sensibilidade e sabedoria.

Gláucio Delaia, pela interlocução, dicas bibliográficas e camaradagem.

André Luiz, pelas conversas e interferências na volta pra casa.

Chiquinha e Lusinete, pela ajuda e delicadeza.

Fred, pelas idéias trocadas e ensaiadas.

Zarvos, Pires, Anna, Flávia, Salga e Marcelhães, Salve!

Meu carinho ao Elvis Presley, cão fiel que me ensina com naturalidade a não levar nada mais a sério que o prazer e a diversão.

Valeu, Waly! 


\section{Resumo}

Assunção, Sergio Carvalho; Cardoso, Marília Rothier (Orientadora). Ficção e friç̧ão em Waly Salomão. Rio de Janeiro, 2008. 104p. Tese de Doutorado - Departamento de Letras, Pontifícia Universidade Católica do Rio de Janeiro.

Este trabalho propõe investigar as marcas que compõem a poesia experimental de Waly Salomão. As experimentações representam uma essencial marca em sua arte. A poesia é vista como permanente produção de um axial ético e mítico que busca fundir as diversas linguagens, assim como a fusão entre a vida e a arte.

\section{Palavras-chave}

Waly; fricção; poesia; alquimia; música. 


\section{Abstract}

Assunção, Sergio Carvalho; Cardoso, Marília Rothier (Advisor). Fiction and friction in Waly Salomão. Rio de Janeiro, 2008. 104p. Doctoral Thesis - Departamento de Letras, Pontifícia Universidade Católica do Rio de Janeiro.

This work proposes to investigate the signals of the experimental poetry's of Waly Salomão. The experimentations represent an essential milestone in his art. His poetry is exposed just as ethical and mythical axis creation's that finds to melt the various esthetical languages, like a fusion between his living experience and his oeuvre.

\section{Keywords}

Waly; friction; poetry; alchemy; music. 


\section{Sumário}

1. três vezes Waly: ecos multifocais

2. caos e metamorfose

2.1. superar a província OU deixa sangrar 14

2.2. a prisão OU qual a dimensão da poesia 19

2.3. me segura OU como prender Proteu

3. ritmo e melodia

3.1. a gênese rítmica da poesia 37

3.2. na esfera da produção: o efêmero e onívoro 43

3.3. fricção e ficção: tensão e fusão 53

4. harmonia alquímica 72

4.1. hélio \& sailormoon: poética experimental 72

4.2. babilaques, música e contracultura: a poesia é o axial 86

5. referências 100

6. anexos 


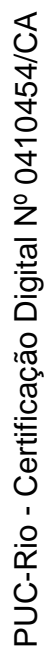

É melhor queimar do que se apagar aos poucos.

Neil Young 